\title{
EXTENSION EVALUATION MODEL OF LAND DESTRUCTION DEGREE IN MINING AREA AND ITS APPLICATION
}

\author{
Hongbo Jin ${ }^{1,2}$, Yuanfang Huang ${ }^{1, *}$, Shiwen Zhang ${ }^{1}$, Guan Gong ${ }^{1,3}$ \\ ${ }^{1}$ Key laboratory of plant-soil interactions, MOE; Key laboratory of soil and water, MOA; \\ College of Resources and Environment, China Agriculture University, Beijing, P. R. China \\ 100193 \\ ${ }^{2}$ Liaoning Technical University, Fuxin, Liaoning province, P. R. China 123000 \\ ${ }^{3}$ Henan Technical University, Jiaozuo, Henan province, P. R. China 454000 \\ * Corresponding author, Address: College of Resource and Environment, China Agriculture \\ University, Beijing, P. R. China 100193, Tel: +86-10-62732963, Email: yfhuang \\ @.china.com
}

Abstract: Taking Renjiazhuang coal mine as the object of study, this paper carries on evaluation to destruction degree in this area by using extension theory and establishing evaluation extension model of land destruction in mining area. Results show that severe destruction area of collapse land in Renjiazhuang coal mine is $112.86 \mathrm{hm}^{2}$, moderate destruction area is $372.27 \mathrm{hm}^{2}$, light destruction area is $723.42 \mathrm{hm}^{2}$, spoiled land belongs to light destruction and its area is $7.09 \mathrm{hm}^{2}$. Our study provides evidence for making countermeasures in destruction land reclamation in mining areas, choosing reclamation technology and carrying on suitability evaluation, etc. It is proved that the extension theory is feasible in evaluation of land destruction in mining areas.

Keywords: extension theory, mining area, destruction, extension model, evaluation

\section{INTRODUCTION}

Coal mining can cause the surface subsidence, land erosion, secondary salinization, swamping, land desertification, decrease of crop yield, additional slope, cracks, etc. Land reclamation in mining areas may alleviate

Please use the following format when citing this chapter:

Jin, H., Huang, Y., Zhang, S. and Gong, G., 2009, in IFIP International Federation for Information Processing, Volume 293, Computer and Computing Technologies in Agriculture II, Volume 1, eds. D. Li, Z. Chunjiang, (Boston: Springer), pp. 233-244. 
human-land conflict and improve the ecological environments of mining area and the surrounding areas. While the land destruction evaluation may provide essential basis for formulating countermeasures of destruction land reclamation, choosing reclamation craft and carrying on the suitability evaluation, it is essentially a evaluation on variation degree of mining area land quality caused by exploitation, revealed the utilization scope and capacity of land (Fabin Li et al., 2006).

The defects of traditional evaluation methods are obvious. For example, they can't eliminate the contradictory or overlapping relationship when selecting indexes. In addition, most of them are based on points, which influence the accuracy and objectivity of evaluation (Tao Guan et al., 2005). However, the superiority of extension evaluation method is obvious because it is the rule and method that studies the extension possibility of things with the formalized model, often used in dealing with contradictory problems (Wen Cai et al., 2000), Meanwhile, it is based on interval, so its result draws closer to the reality. Many studies have applied this theory in many domains' evaluation studies, including rock mass side slope stability judgment(Zhiqiang Kang et al., 2007), the decision-making evaluation toland development and reorganization project (Tao Guan et al., 2005), quantification evaluation to building damage (Limin Liu et al., 2004), classified recognition of harmful insects in stored grain (Jinli Yuan et al., 2004), rank evaluation to water quality (Yong Ye et al., 2007), etc. While in the aspect of destruction land evaluation in mining area, this theory's application is still a blank. The objective of this study is to apply the extension theory in land destruction evaluation in mining areas, establish the extension model and index system of land destruction evaluation in mining areas and carry on example analysis.

\section{BASIC PRINCIPLES OF EXTENSION EVALUTION METHOD}

Extension theory was put forward by Cai et al. (1983) through combining the matter-element theory with extension set. The research objects of extension are the contradictory problems in the objective world Research contents are the rules and methods of dealing with contradictory problems. A combination of extention theory with other domains' theories caused corresponding new knowledge and formed the application of extension. Based on extension theory, some extension methods have been developed such as matter-element extension method, matter-element shifting method and priority evaluation method. The combination of these methods with those in other domains formed corresponding extension engineering method, 
which has been applied in economy, management, decision-making and process control (Wen Cai et al., 1998, 1999).

\section{$2.1 \quad$ Matter-element}

Matter-element is a triple composed of thing, characteristic and characteristic value of the thing. Its expression is $R=$ (thing , characteristic, value $)=(N, c, V)$. The 2-element group composed of $c$ and $V$ is called characteristic element and its expression is $M=(c, V)$. The thing is the name of thing in matter-element theory and its expression is $I(N)$, The characteristic is the thing's characteristic of nature, function, condition, etc., and its expression is $V(c)$ or $V=(a, b)$.

\subsection{Theory of extension set}

The main content of extension set is to quantitatively describe thing's variability by establishing correlation function. Its basic pattern is defining the distance of point to interval firstly and then establishing correlation function and describing thing's variability by calculating. The following relationship can be got by supposing $x$ is any point in real domain $(-\infty,+$ $\infty)$ and $X=(a, b)$ is the real interval in this domain:

$$
\rho(x, X)=\left|x-\frac{a+b}{2}\right|-\frac{1}{2}(b-a)
$$

$\rho(x, X)$ is the distance of $x$ to $X$.The distance of $x$ to two intervals $X_{0}=(a, b)$ and $X=(c, d)$ is expressed by $D\left(x, X_{0}, X\right)$. The equation of $D\left(x, X_{0}, X\right)$ is written as

$$
D\left(x, X_{0}, X\right)=\left\{\begin{array}{cc}
\rho(x, X)-\rho\left(x, X_{0}\right) & x \notin X_{0} \\
-1 & x \in X_{0}
\end{array}\right.
$$

By supposing $X_{0}=(a, b), X=(c, d)$ and $X_{0} \subset X$, the correlation function between them can be expressed by $K(x, X)$. The expression of $K(x, X)$ is

$$
K(x, X)=\frac{\rho(x, X)}{D\left(x, X_{0}, X\right)}
$$




\subsection{Establishment of extension model}

First, the value scope of each evaluation factor is determined. Next, correlation function is established to evaluate each index. Then they are combined to the weight of each factor of evaluation index set and finally used to determine the rank. The basic steps are as follows (see the details in the establishment of extension evaluation model of land destruction in mining areas): (1)establishing matter-element model of segment field and classic field of system; (2)establishing correlation function and calculate correlation degree; (3) establishing the model of matter-element to be evaluated; (4) Determining the weight of each evaluation index; (5) Determining the correlation degree of the thing to be evaluated; (6) Determining the rank of the thing to be evaluated.

\section{ESTABLISHMENT OF EXTENSION EVALUATION MODEL OF LAND DESTRUCTION IN MINING AREAS}

According to the basic principles of extension evaluation method, the extension evaluation model of land destruction in mining areas can be established by following steps.

(1)Establishing matter-element model of segment field and classic field of system

$$
R_{p}=(P, c, v)=\left[\begin{array}{ccc}
P & c_{1} & v_{p 1} \\
& c_{2} & v_{p 2} \\
\ldots & \ldots \\
& c_{n} & v_{p n}
\end{array}\right]=\left[\begin{array}{ccc}
P & c_{1} & <a_{p 1}, b_{p 1}> \\
& c_{2} & <a_{p 2}, b_{p 2}> \\
\ldots & \ldots \\
c_{n} & <a_{p n}, b_{p n}>
\end{array}\right]
$$

The above is matter-element model of segment field of system, $P$ in this formula is all the ranks of land destruction in mining areas, $v_{p i}$ is all the values' scope of corresponding index $c_{i}$, that is the segment field $<a_{p i}, b_{p i}>$ of $P$.

$$
R_{o j}=\left(N_{o j}, C_{o}, V_{o}\right)=\left[\begin{array}{ccc}
N_{o j} & c_{1} & v_{o j 1} \\
& c_{2} & v_{o j 2} \\
& \ldots & \cdots \\
& c_{n} & v_{o j n}
\end{array}\right]=\left[\begin{array}{ccc}
p & c_{1} & <a_{o j 1}, b_{o j 1}> \\
& c_{2} & <a_{o j 2}, b_{o j 2}> \\
\ldots & \ldots \\
& c_{n} & <a_{o j n}, b_{o j n}>
\end{array}\right]
$$

The above is matter-element model of classic field of system, $N_{o j}$ is the rank criteria of land destruction in mining areas $(j=1,2,3$ represent light, 
moderate and severe destruction respectively), $v_{o j i}$ is all the values' scope of corresponding index $c_{i}$, namely the classic field $\left\langle a_{o j i}, b_{o j i}\right\rangle$.

(2)Establishing correlation function and calculating correlation degree

The correlation degree is the measurement of relevance between things and between factors. Its expression is as follows:

$$
\left\{\begin{array}{l}
K_{j i}=-\frac{\rho\left(v_{i}, v_{o j i}\right)}{\left|v_{o j i}\right|} \\
K_{j i}=\frac{\rho\left(v_{i}, v_{o j i}\right)}{\rho\left(v_{i}, v_{p i}\right)-\rho\left(v_{i}, v_{o j i}\right)}
\end{array}\right.
$$

(3)Establishing the model of matter-element for evaluation

The evaluation data information obtained by detection, collection and analysis are represented by the matter-element $R_{o} . x_{i}$ represents the concrete numerical values corresponding to the evaluation index of the unit to be evaluated, $P_{0}$ represents evaluation object.

$$
R_{o}=\left[\begin{array}{ccc}
P_{0} & c_{1} & x_{1} \\
& c_{2} & x_{2} \\
& \cdots & \cdots \\
& c_{n} & x_{n}
\end{array}\right]
$$

(4)Determining the weight of each evaluation index

This study uses the set-valued statistics method to determine the weight of each evaluation index. This method can reflect the objective reality reasonably and give proper consideration on both the fuzziness and subjective judgment factor in the evaluation. It operates quite simply and is easy to spread. Balachandra et al. (1995) put forward the principles of this method.

(5)Determining the correlation degree of each destruction rank of mining area land for evaluation.

According to the weight determined by step (4), after calculating correlation degree, its expression is as follows:

$$
K_{j}\left(p_{o}\right)=\sum_{i=1}^{n} w_{i} K_{j}\left(x_{i}\right)
$$

This formula represents destruction rank of mining area land to be evaluated and its degree.

(6)Determining the destruction rank of mining area land

If $K_{j 0}=\max _{j_{0} \in(1,2,3)} K_{j}\left(p_{0}\right)$, the destruction rank of the unit to be evaluated belongs to $j_{0}$. 


\section{APPLICATION EXAMPLE}

Taken Renjiazhuang coal mine as an example, destruction degree evaluation to mining area land is introduced based on extension theory. Renjiazhuang coal mine is a new mine without production yet. In-situ investigation and the verification of Ningxia Hui autonomous region and the local land resources management section shows no destruction land such as crack and collapse caused by coal mine production at present .

\subsection{Construction of index system and evaluation criteria}

The mining process causes the destruction of land resources. Destruction type is different, therefore, evaluation index is also different. For example, the main type of destruction land is collapse and spoiled land. For collapse land, there will be some changes with the exploration of mine field macroscopically, e.g., collapse, crack and water accumulation, etc; The soil properties will also change microscopically, e.g., soil nutrient. Correspondingly, For spoiled land, there will also be certain change. To evaluate the degree of land destruction accurately, we should choose indexes that can reflect destruction degree of mining area land directly or indirectly reasonably.

Table 1. Evaluation indexes of land destruction in mining areas and criteria

\begin{tabular}{|c|c|c|c|c|c|}
\hline \multirow{2}{*}{$\begin{array}{l}\text { Destruction } \\
\text { type }\end{array}$} & \multirow{2}{*}{$\begin{array}{l}\text { evaluation } \\
\text { factor }\end{array}$} & \multirow{2}{*}{$\begin{array}{l}\text { evaluation } \\
\text { factor }\end{array}$} & \multicolumn{3}{|c|}{$\begin{array}{l}\text { evaluation } \\
\text { rank }\end{array}$} \\
\hline & & & I & II & III \\
\hline \multirow{10}{*}{$\begin{array}{l}\text { collapse } \\
\text { land }\end{array}$} & \multirow{3}{*}{$\begin{array}{c}\text { surface } \\
\text { deformation }\end{array}$} & collapse depth & $>50 \mathrm{~cm}$ & $50 \sim 200 \mathrm{~cm}$ & $>200 \mathrm{~cm}$ \\
\hline & & collapse area & $<100 \mathrm{~m}^{2}$ & $100 \sim 1000 \mathrm{~m}^{2}$ & $>1000 \mathrm{~m}^{2}$ \\
\hline & & $\begin{array}{l}\text { side slope degree of } \\
\text { collapse }\end{array}$ & $<25^{\circ}$ & $25^{\circ} \sim 35^{\circ}$ & $>35^{\circ}$ \\
\hline & \multirow{2}{*}{$\begin{array}{l}\text { surface } \\
\text { crack }\end{array}$} & crack width & $10 \mathrm{~cm}$ & $10 \sim 30 \mathrm{~cm}$ & $30 \mathrm{~cm}$ \\
\hline & & crack spacel & $>50 \mathrm{~m}$ & $30 \sim 50 \mathrm{~m}$ & $<30 \mathrm{~m}$ \\
\hline & \multirow{3}{*}{ soil properties } & soil erodibility & $<10 \%$ & $10 \% \sim 30 \%$ & $>30 \%$ \\
\hline & & soil salinization & none & salinization & saline soil \\
\hline & & decline of soil fertility & $<15 \%$ & $15 \% \sim 40 \%$ & $>40 \%$ \\
\hline & \multirow{2}{*}{$\begin{array}{l}\text { hydrological } \\
\text { condition } \\
\text { stability }\end{array}$} & $\begin{array}{l}\text { status of water } \\
\text { accumulation }\end{array}$ & none & seasonal & long-term \\
\hline & & stability & stable & comparatively stable & unstable \\
\hline \multirow{7}{*}{$\begin{array}{l}\text { pressure } \\
\text { occupied } \\
\text { land }\end{array}$} & \multirow{3}{*}{$\begin{array}{l}\text { surface } \\
\text { change }\end{array}$} & spoiled area & $<10000 \mathrm{~m}^{2}$ & $10000 \sim 50000 \mathrm{~m}^{2}$ & $>50000 \mathrm{~m}^{2}$ \\
\hline & & side slope degree & $<25^{\circ}$ & $25^{\circ} \sim 35^{\circ}$ & $>35^{\circ}$ \\
\hline & & $\begin{array}{c}\text { increase of gravel } \\
\text { content }\end{array}$ & $<10 \%$ & $10 \% \sim 30 \%$ & $>30 \%$ \\
\hline & \multirow{3}{*}{$\begin{array}{l}\text { properties of } \\
\text { pressure } \\
\text { occupied land }\end{array}$} & $\begin{array}{l}\text { decline of organic } \\
\text { content }\end{array}$ & $<15 \%$ & $15 \% \sim 65 \%$ & $>65 \%$ \\
\hline & & $\begin{array}{l}\text { pollution of toxic } \\
\text { element }\end{array}$ & light & moderate & severe \\
\hline & & $\mathrm{pH}$ & $6.5 \sim 7.5$ & $\begin{array}{c}4 \sim 6.5 \\
7.5 \sim 8.5\end{array}$ & $<4,>8.5$ \\
\hline & stability & stability & stable & comparatively stable & unstable \\
\hline
\end{tabular}

Considering Renjiazhuang coal mine's actual situation and combining to general requirements of choosing indexes, we choose corresponding indexes 
(Table 1).According to $<$ Land Management Law of the People's Republic of China > in 2004 and < Land Reclamation Regulations of the State Council > in 1998, Evaluation rank of mine land's destruction degree is devided into 3level criterion: level I (light destruction); level II (moderate destruction); level III (severe destruction).

\subsection{Division of evaluation unit}

The evaluation unit is the special object whose natural attribute and socioeconomic attribute of land is basically consistent. It is the land unit that has special characteristics and the basic area used in charting. Its basic requirements of division is: (1)the properties in the unit are relatively homogeneous or close; (2)there are differences between units, it reflects the differences of land in certain time and space objectively; (3)the units should have certain comparability. The land resources in mining area have the particularity, its evaluation area is relatively small and the soil type and the land utilization type are relatively consistent. So the division of evaluation unit of destruction land in mining area is mainly based on destruction type. At the same time, we should give proper consideration to the basic consistency of land characteristics and utilization direction of reclamation and improvement ways in the same evaluation unit type.

Because the area of spoiled land is small and its properties are relatively simplistic, we take its whole as an evaluation unit. We use overlap method to divide the evaluation unit in collapse land. Here is the detail: take land utilization map of the mining area as base map, according to the destruction prediction of mining area, draw the distribution map of dominant factors (collapse depth, surface crack e.g.) that reflect the destruction degree, at last, by overlapping forms small polygons and by merging forms evaluation unit (see fig. 1).

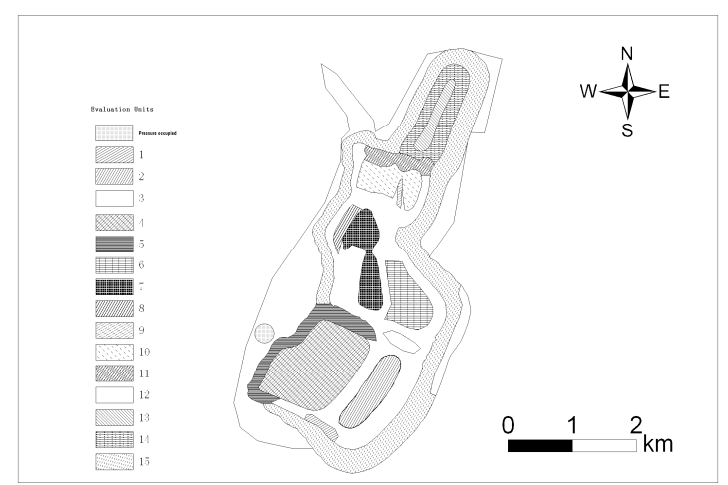

Fig. 1. Evaluation unit map of destruction land in Renjiazhuang mining area 


\subsection{Determine the segment field and classic field of evaluation indexes}

The determination of upper limit and lower limit of segment field should depend on experts' experiences, that is experts give the maximum values and minimum values of each indexes. Because the field of each index is not all the same, Smaller the values of some evaluation indexes are, higher their destruction ranks are (crack interval), Bigger the values of some evaluation indexes are, higher their destruction ranks are, we deal with each index with normalization and non-dimension (Qiuji Chen et al., 2006). Thus , according to table 1 , we can determine the segment field and classic field of evaluation indexes as in table 2.

Table 2. Classic field and segment field of evaluation indexes

\begin{tabular}{|c|c|c|c|c|c|c|}
\hline \multirow{2}{*}{$\begin{array}{l}\text { Destruction } \\
\text { Type }\end{array}$} & \multirow{2}{*}{$\begin{array}{l}\text { Evaluation } \\
\text { Factor }\end{array}$} & \multirow{2}{*}{$\begin{array}{l}\text { Evaluation } \\
\text { Factor }\end{array}$} & \multicolumn{3}{|c|}{ Classic Field } & \multirow{2}{*}{$\begin{array}{l}\text { Segment } \\
\text { Field }\end{array}$} \\
\hline & & & I & II & III & \\
\hline \multirow{10}{*}{$\begin{array}{l}\text { Collapse } \\
\text { Land }\end{array}$} & \multirow{3}{*}{$\begin{array}{l}\text { surface } \\
\text { deformation }\end{array}$} & collapse depth & $0 \sim 0.14$ & $0.14 \sim 0.42$ & $0.57 \sim 1$ & $0 \sim 1$ \\
\hline & & collapse area & $0 \sim 0.05$ & $0.05 \sim 0.50$ & $0.50 \sim 1$ & $0 \sim 1$ \\
\hline & & $\begin{array}{l}\text { side slope } \\
\text { degree of } \\
\text { collapse }\end{array}$ & $0 \sim 0.36$ & $0.36 \sim 0.50$ & $0.50 \sim 1$ & $0 \sim 1$ \\
\hline & \multirow{2}{*}{$\begin{array}{l}\text { surface } \\
\text { crack }\end{array}$} & crack width & $0 \sim 0.20$ & $0.20 \sim 0.60$ & $0.60 \sim 1$ & $0 \sim 1$ \\
\hline & & crack spacel & $0.30 \sim 0.50$ & $0.50 \sim 0.70$ & $0.70 \sim 1$ & $0.30 \sim 1$ \\
\hline & \multirow{3}{*}{$\begin{array}{l}\text { soil } \\
\text { properties }\end{array}$} & soil erodibility & $0 \sim 0.17$ & $0.17 \sim 0.50$ & $0.50 \sim 1$ & $0 \sim 1$ \\
\hline & & soil salinization & $0.10 \sim 0.30$ & $0.30 \sim 0.70$ & $0.70 \sim 1$ & $0.10 \sim 1$ \\
\hline & & $\begin{array}{l}\text { decline of soil } \\
\text { fertility }\end{array}$ & $0 \sim 0.17$ & $0.17 \sim 0.44$ & $0.44 \sim 1$ & $0 \sim 1$ \\
\hline & $\begin{array}{l}\text { hydrological } \\
\text { condition }\end{array}$ & $\begin{array}{l}\text { status of water } \\
\text { accumulation }\end{array}$ & $0.10 \sim 0.30$ & $0.30 \sim 0.70$ & $0.70 \sim 1$ & $0.10 \sim 1$ \\
\hline & stability & stability & $0.10 \sim 0.30$ & $0.30 \sim 0.70$ & $0.70 \sim 1$ & $0.10 \sim 1$ \\
\hline \multirow{8}{*}{$\begin{array}{l}\text { Pressure } \\
\text { Occupied } \\
\text { Land }\end{array}$} & \multirow{2}{*}{$\begin{array}{l}\text { surface } \\
\text { change }\end{array}$} & \multirow{2}{*}{$\begin{array}{l}\text { spoiled area } \\
\text { side slope } \\
\text { degree }\end{array}$} & $0 \sim 0.01$ & $0.01 \sim 0.1$ & $0.1 \sim 1$ & $0 \sim 1$ \\
\hline & & & $0 \sim 0.33$ & $0.33 \sim 0.47$ & $0.47 \sim 1$ & $0 \sim 1$ \\
\hline & \multirow{5}{*}{$\begin{array}{l}\text { properties of } \\
\text { pressure } \\
\text { occupied land }\end{array}$} & \multirow{4}{*}{$\begin{array}{l}\text { increase of } \\
\text { gravel content } \\
\text { decline of } \\
\text { organic content } \\
\text { pollution of } \\
\text { toxic element }\end{array}$} & $0 \sim 0.17$ & $0.17 \sim 0.50$ & $0.50 \sim 1$ & $0 \sim 1$ \\
\hline & & & $0 \sim 0.16$ & $0.16 \sim 0.68$ & $0.68 \sim 1$ & $0 \sim 1$ \\
\hline & & & $0.10 \sim 0.30$ & $0.30 \sim 0.70$ & $0.70 \sim 1$ & $0.10 \sim 1$ \\
\hline & & & $0.25 \sim 0.35$ & $\begin{array}{c}0.35 \sim 0.6 \\
(\text { acid condition })\end{array}$ & $\begin{array}{c}0.60 \sim 1 \\
\quad(\text { acid } \\
\text { condition })\end{array}$ & $0.25 \sim 1$ \\
\hline & & $\mathrm{pH}$ & $0.46 \sim 0.53$ & $\begin{array}{l}0.53 \sim 0.61 \\
\quad(\text { alkalinity } \\
\text { condition })\end{array}$ & $\begin{array}{l}\text { condition) } \\
0.61 \sim 1 \\
\text { (alkalinity } \\
\text { condition) } \\
\end{array}$ & $0.46 \sim 1$ \\
\hline & stability & stability & $0.10 \sim 0.30$ & $0.30 \sim 0.70$ & $0.70 \sim 1$ & $0.10 \sim 1$ \\
\hline
\end{tabular}




\subsection{Data processing}

The data in the example are the various indexes' prediction values of each evaluation unit, including the values of collapse land and spoiled land. The details are as in table 3 and table 4 . Because of the length limit, only the values of some units are listed.

Table 3. Prediction values of indexes in collapse land of some evaluation units

\begin{tabular}{cccccccccccc}
\hline \multicolumn{2}{l}{ evaluation unit $\mathrm{x}_{1}(\mathrm{~cm})$} & $\mathrm{x}_{2}\left(\mathrm{~m}^{2}\right)$ & $\mathrm{x}_{3}\left({ }^{\circ}\right)$ & $\mathrm{x}_{4}(\mathrm{~cm})$ & $\mathrm{x}_{5}(\mathrm{~m})$ & $\mathrm{x}_{6}(\%)$ & $\mathrm{x}_{7}$ & $\mathrm{x} 8(\%)$ & $\mathrm{x}_{9}$ & $\mathrm{x}_{10}$ & Area $\left(\mathrm{hm}^{2}\right)$ \\
\hline 1 & 101.5 & 1060 & 53.2 & 39.5 & 43 & 41.4 & none & 66.6 & seasonal & unstable & 7.25 \\
2 & 31.5 & 320 & 18.9 & 10.5 & 55 & 12 & none & 10.8 & seasonal & stable & 46.94 \\
3 & 14 & 1520 & 13.3 & 15.5 & 38 & 9 & none & 11.7 & seasonal & stable & 147.01 \\
\hline
\end{tabular}

Note: $x 1$ :collapse depth, $x 2$ :collapse area, $x 3$ :side slope degree of collapse, $x 4:$ crack width, 5 : crack space,$x 6$ :soil erodibility,$x 7$ :soil salinization, $x 8$ :decline of soil fertility ,x9:status of water accumulation,x10:stability.

Table 4. Prediction values of indexes in spoiled land

\begin{tabular}{ccccccccc}
\hline $\begin{array}{c}\text { evaluation } \\
\text { unit }\end{array}$ & $\begin{array}{c}\mathrm{x}_{1} \\
\mathrm{~m}^{2}\end{array}$ & $\begin{array}{c}\mathrm{x}_{2} \\
\circ\end{array}$ & $\mathrm{x}_{3}$ & $\mathrm{x}_{4}(\%)$ & $\mathrm{x}_{5}$ & $\mathrm{x}_{6}$ & $\mathrm{x}_{7}$ & $\begin{array}{c}\text { area } \\
\mathrm{hm}^{2}\end{array}$ \\
\hline 1 & 7.09 & 70 & 13.2 & 14.25 & light & 4.8 & stable & 7.09 \\
\hline
\end{tabular}

Note: $x_{1}$ :spoiled area , $x_{2}$ :side slope degree,$x_{3}$ :increase of gravel content,$x_{4}$ : decline of organic content, $x_{5}:$ :pollution of toxic element, $x_{6}: p H, x_{7}:$ stability.

By processing the data in table 3 and table 4 with normalization and nondimension, we get the data shown in table 5 and table 6 .

Table 5. Prediction values of indexes in collapse land of some evaluation units

\begin{tabular}{ccccccccccc}
\hline $\begin{array}{c}\text { evaluation } \\
\text { unit }\end{array}$ & $\mathrm{x}_{1}$ & $\mathrm{x}_{2}$ & $\mathrm{x}_{3}$ & $\mathrm{x}_{4}$ & $\mathrm{x}_{5}$ & $\mathrm{x}_{6}$ & $\mathrm{x}_{7}$ & $\mathrm{x}_{8}$ & $\mathrm{x}_{9}$ & $\mathrm{x}_{10}$ \\
\hline 1 & 0.29 & 0.53 & 0.76 & 0.79 & 0.57 & 0.69 & 0.27 & 0.74 & 0.15 & 0.82 \\
2 & 0.09 & 0.16 & 0.27 & 0.21 & 0.45 & 0.20 & 0.26 & 0.12 & 0.24 & 0.27 \\
3 & 0.04 & 0.76 & 0.19 & 0.31 & 0.62 & 0.15 & 0.23 & 0.13 & 0.11 & 0.26 \\
\hline
\end{tabular}

Note: the meaning of the symbols in the table is the same with in table 3

Table 6. Prediction values of indexes in spoiled land

\begin{tabular}{cccccccc}
\hline evaluation unit & $\mathrm{x}_{1}$ & $\mathrm{x}_{2}$ & $\mathrm{x}_{3}$ & $\mathrm{x}_{4}$ & $\mathrm{x}_{5}$ & $\mathrm{x}_{6}$ & $\mathrm{x}_{7}$ \\
\hline 1 & 0.71 & 0.93 & 0.22 & 0.15 & 0.22 & 0.52 & 0.15 \\
\hline
\end{tabular}

Note: the meaning of the symbols in the table is the same with in table 4

\subsection{Establishment of matter-element to be evaluated model}

The data of an evaluation unit in a certain collapse land were got. Collapse depth is $101.5 \mathrm{~cm}$, collapse area is $1060 \mathrm{~m}^{2}$, side slope degree of collapse is 
$53.2^{\circ}$, crack width is $39.5 \mathrm{~cm}$, crack space is $43 \mathrm{~m}$, soil erodibility is $41.4 \%$, there is no salinization in soil, decline of soil fertility is $66.6 \%$, and seasonal water accumulation is unstable. We get the matter-element model of the unit to be evaluated with normalization and non-dimension as follow.

$$
R_{o}=\left[\begin{array}{ccc}
P_{0} & c_{1} & 0.29 \\
& c_{2} & 0.53 \\
& c_{3} & 0.76 \\
& c_{4} & 0.79 \\
& c_{5} & 0.57 \\
& c_{6} & 0.69 \\
& c_{7} & 0.27 \\
& c_{8} & 0.74 \\
& c_{9} & 0.15 \\
& c_{10} & 0.82
\end{array}\right]
$$

The same as above,we get the matter-element models of the other 14 units of collapse land and spoiled land to be evaluated. Because of the limit of space, we leave them out.

\subsection{Evaluation process}

(1)According to formula(5), we can get the values of correlation function shown in table 7 and table 8 . The tables just show the results of a certain collapse land and spoiled land. We leave out the values of other units because of space.

Table 7. Correlation function values of indexes' ranks in collapse land

\begin{tabular}{ccccccccccc}
\hline $\begin{array}{c}\text { Value of correlation } \\
\text { function }\end{array}$ & $\mathrm{x}_{1}$ & $\mathrm{x}_{2}$ & $\mathrm{x}_{3}$ & $\mathrm{x}_{4}$ & $\mathrm{x}_{5}$ & $\mathrm{x}_{6}$ & $\mathrm{x}_{7}$ & $\mathrm{x}_{8}$ & $\mathrm{x}_{9}$ & $\mathrm{x}_{10}$ \\
\hline$K_{1}$ & -0.28 & -0.49 & -0.50 & -0.59 & -0.12 & -0.54 & 0.25 & -0.67 & 0.10 & -0.73 \\
$K_{2}$ & 0.21 & -0.04 & -0.36 & -0.18 & 0.15 & -0.24 & 0.25 & -0.52 & -0.90 & -0.37 \\
$K_{3}$ & -0.60 & 0.04 & 0.36 & 0.18 & -0.43 & 0.24 & 0.75 & 0.48 & -0.97 & 0.37 \\
\hline
\end{tabular}

Note: the meaning of the symbols in the table is the same with in table 3

Table 8. Correlation function values of indexes' ranks in spoiled land

\begin{tabular}{cccccccc}
\hline $\begin{array}{c}\text { Value of correlation } \\
\text { function }\end{array}$ & $\mathrm{x}_{1}$ & $\mathrm{x}_{2}$ & $\mathrm{x}_{3}$ & $\mathrm{x}_{4}$ & $\mathrm{x}_{5}$ & $\mathrm{x}_{6}$ & $\mathrm{x}_{7}$ \\
\hline$K_{1}$ & -0.71 & -0.90 & -0.19 & 0.06 & 0.40 & -0.39 & 0.25 \\
$K_{2}$ & -0.68 & -0.87 & 0.15 & -0.06 & -0.40 & 0.32 & -0.75 \\
$K_{3}$ & 0.32 & 0.13 & -0.56 & -0.78 & -0.80 & -0.23 & -0.92 \\
\hline
\end{tabular}

Note: the meaning of the symbols in the table is the same with in table 4

(2)Determine the weight of each evaluation index 
We use the set-valued statistics method to get the weight of each evaluation index as follows.

$\mathrm{W}_{\text {collapse }}=\{0.18,0.17,0.11,0.09,0.07,0.03,0.03,0.03,0.14,0.15\}$

$\mathrm{W}_{\text {pressure }}=\{0.03,0.26,0.10,0.06,0.19,0.13,0.23\}$

(3) Determination of the correlation degree of evaluation unit and judgment of destruction rank

Taking a certain evaluation unit of collapse land as an example, according to formula (7), we can get the correlation degree about 3 levels - light destruction, moderate destruction and severe destruction. They respectively are-0.37、 -0.21 and $-0.11 . K_{j 0}=\max _{j_{0} \in(1,2,3)} K_{j}\left(p_{0}\right)=-0.11$, so the rank of this evaluation unit belongs to severe destruction. Likewise, we can determine the destruction rank of spoiled land and other evaluation units of collapse land.

According to the above process, it can be predicted that in Renjiazhuang coal mine the mining will cause light destruction area $723.42 \mathrm{hm}^{2}$, moderate destruction area $372.27 \mathrm{hm}^{2}$ and severe destruction area $112.86 \mathrm{hm}^{2}$. Spoiled land belongs to light destruction and its area is $7.09 \mathrm{hm}^{2}$. The distribution of destruction rank in this mining area is showed in fig. 2. This evaluation result may provide favourable evidence for formulating countermeasure of destruction land reclamation, choosing reclamation craft and carrying on the suitability evaluation.

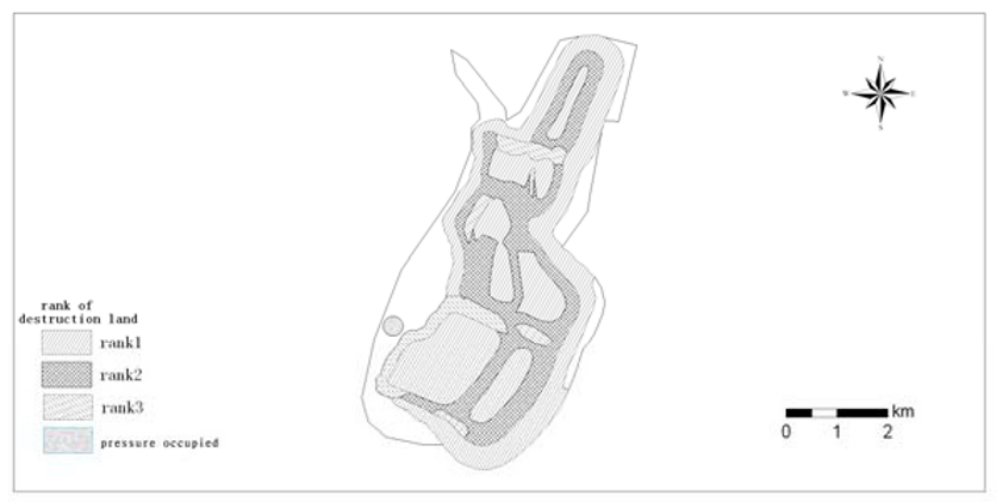

Fig.2. predicted map of land destruction situation of Renjiazhuang coal mine 


\section{ACKNOWLEDGEMENTS}

The authors acknowledge the financial support provided by the National Natural Science Foundation of China (No. 40671084), The 863 Program (2008AA10Z216), Beijing Natural Science Foundation (6072017), the National Key Technologies R\&D Program (2006BDA10A01), and by the Program for New Century Excellent Talents in University (NCET-06-0107).

\section{REFERENCES}

Balachandra R, Brock Hoff K. Are R\&D project termination factors universal?, Res Technical Management, 1995, (8):31-36

Fabin Li,Hechao Li,Jiayun Zhou. Study on evaluation method of destruction degree of land in mining areas, Mining Technology, 2006,6 (2):25-28

Jinli Yuan,Haiyan Ji,Zhitao Guo. Classification and recognition of stored-grain pests by using extension engineering method, Agricultural Engineering Journal, 2004,20(5):170-172

Limin Liu,Hanlong Liu, Chuanjie Lian. Matter-element model for buildings'damage grade evaluation and its application caused by mining subsidence, Coal Journal, 2004,29(1):1721

Qiuji Chen,Changhua Liu,Hongquan Xie. Application of extension method to land reclamation in mining area, Journal of Liaoning Technical University, 2006, 25(2):304-307

Tao Guan,Wanjun Yu,Yongyang Shen. Decision-making of land development and consolidation project based on extension evaluation method, Agricultural Engineering Journal, 2005, 21(3):71-74

Wen Cai,Chunyan Yang,Weichu Lin. Extension engineering method, Science Publishing House, 2000:207-209

Wen Cai. Extenics Review, Systems Engineering-Throry \& Practice, 1998,18(1):76-84.

Wen Cai. Extension Theory and Its Application, Chinese Science Bulletin, 1999,44(17):15381548

Yong Ye,Baoming Chi,Fengzhi Shi. Application of matter-element extension for groundwater environment quality evaluation, Journal of Soil and Water Conservation, 2007,4(2):52-54

Zhiqiang Kang,Hui Zhou,Xiating Feng. Evaluation of high rock slope quality based on theory of extenics, Northeast University Journal, 2007,28(12):1770-1774 